I Universidade Estadual de Campinas (Unicamp), Instituto de Filosofia e Ciências Humanas (IFCH), Departamento de Sociologia, Campinas, SP, Brasil mariomed@unicamp.br

Mário Augusto Medeiros da Silva'

\title{
ÓRBITAS SINCRÔNICAS: SOCIÓLOGOS E INTELECTUAIS NEGROS EM SÃO PAULO, ANOS 1950-1970
}

\begin{abstract}
APROXIMAÇÕES INICIAIS
A aproximação entre cientistas sociais e ativistas negros paulistanos já se havia iniciado nos anos I940 e I950. Como exemplo inicial, destaque-se o papel de Roger Bastide na organização da Pesquisa Unesco sobre Relações Raciais em São Paulo (Maio, I997) e seu papel distintivo para conseguir construir um esforço de pesquisa participante (Cardoso, 2008). As pesquisas sobre religiões afro-brasileiras, imprensa negra e poesia afro-brasileira (Bastide, I973), com publicação inicial em I94I, efetuadas pelo sociólogo francês tornaram-no um interlocutor respeitado no meio negro organizado paulistano daquelas décadas, sendo talvez o elo mais sólido para que o relatório sobre as relações raciais em São Paulo fosse possível. Em trabalho anterior, sugeri que se configuraria um encontro na encruzilhada social (Silva, 2013), entre esses cientistas sociais e os ativistas negros. Observe-se, por exemplo, uma fonte pouco usual: a homenagem póstuma a Bastide, publicada na Revista do IEB, tendo uma das mesas sido composta por depoimentos de velhos e novos ativistas das associações negras paulistanas, conhecidos e amigos do sociólogo francês: Raul Joviano do Amaral, José Correia Leite, Jaime de Aguiar e Eduardo de Oliveira e Oliveira. O relato de Amaral é distintivo:
\end{abstract}

Estávamos na década de 1940 a 50. Num antigo casarão, transformado em casa de escritório, que ainda resiste ao tempo, Bastide me conheceu [...] foi o Mestre que de mim se aproximou. Naquele casarão imperial da rua Formosa, na Capital Paulista, funcionava a Associação "José do Patrocínio", entidade devotada à defesa 
da gente negra [...] semanalmente eu proferia uma aula de orientação histórica-educativa para um grupo de senhoritas e rapazes selecionados [...] Numa dessas tertúlias despretenciosas[sic], entre outros assistentes brancos e pretos, notei a presença de um cidadão de porte pequeno fisicamente, que parecia absorver minhas pobres palavras e concordar com os conceitos e apreciações apresentados. A cada encontro de nossos olhares, o cidadão acenava com a cabeça em sinal de aprovação ou concordância. Concluída [a] exposição dessa noite [...] o circunstante referido, após formular com naturalidade algumas questões pertinentes ao tema que fora tratado, num português que denunciava o estrangeiro, inquiriu-me [se Amaral era sociólogo]. Nesse instante, um jovem participante da caravana do cidadão, o futuro acadêmico e condutor de movimento, falecido Jorge Prado Teixeira, negro retinto que provinha de Ribeirão Preto, para ingressar na Faculdade de Filosofia, encarregou-se da apresentação formal [...] Claro que conhecia, de referência, o apresentado. Lera alguns de seus trabalhos. Mas a emoção do contacto direto com o eminente especialista bem pode ser calculada. Desmanchei-me em desculpas e justificativas ante o Mestre, alegando minha condição de curioso, de autodidata da Sociologia e das Ciências Sociais. Expliquei-lhe que cursara a Escola de Sociologia e Política, no seu início, muito mais preocupado com a disciplina que me fascina - a Estatística [...] Comecei, então, a ter contatos mais frequentes com o Mestre, ora na Faculdade, ora em meu escritório, ora em minha casa, que ele honrava [...] Mais intensa e mais íntima se tornou a convivência com Bastide quando Mário Wagner Vieira da Cunha - meu colega na Comissão do Serviço Civil do Estado - anunciara-me a próxima realização dos estudos regionais sobre o negro, sob os auspícios da Unesco, pesquisas coordenadas por Bastide com o inconfundível concurso de Florestan Fernandes e assessoramento preciso de Lucila Hermann (Amaral, 1978).

De maneira semelhante a Bastide, poucos anos depois, a socióloga Virgínia Leone Bicudo (20I0) defenderia a primeira tese de mestrado em relações raciais na Escola Livre de Sociologia e Política. O Estudo de atitudes raciais de pretos e mulatos em São Paulo, sob orientação de Donald Pierson, não teria sido possível sem o emprego do método de pesquisa de que Bicudo se valeu - estudo de atitudes e processos de socialização - para conhecer os mecanismos objetivos e subjetivos do preconceito e discriminação racial. Ela inova ao empregar o método, como demonstrou Janaína Damaceno Gomes (2013), ao inserir a fala dos sujeitos entrevistados, explicitando em diversos espaços cotidianos, privados e públicos, a experiência e internalização dos comportamentos discriminatórios e da socialização do preconceito (nas relações afetivas matrimoniais e sexuais, nos ambientes escolares e de trabalho, na frequência aos espaços públicos da cidade, na formação de sociedades exclusivas ou de participação interétnica etc.).

Bicudo, para tanto, de maneira pioneira, entrevistou antigos membros da Frente Negra Brasileira (I93 I - I937) e analisou seu jornal A Voz da Raça, trocando os nomes de sujeitos e instituições. Infelizmente, sua tese levou 65 anos para ser publicada e ganhar o devido reconhecimento, sem outros desdobramentos na área de sociologia (Silva, 20I I; Gomes, 20I3). Essas duas circunstâncias podem não ter sido as únicas relações e aproximações estabelecidas entre cientistas sociais e movimentos negros em São Paulo. De toda maneira, o objeto deste arti- 
go tem alinhavos de pano de fundo bastante interessantes para discutir o que vem adiante. Esses exemplos podem ajudar a construir aspectos dos argumentos seguintes.

Entre o final dos anos I950 e o decorrer dos I970, um conjunto de cientistas sociais uspianos, junto de outros intelectuais da capital paulista, manteve relações e/ou aproximações de pesquisa, pessoais e de ativismo antirracista com o associativismo negro paulistano. Nesse cenário, destacam-se as figuras de Florestan Fernandes (I920-I995) e da Associação Cultural do Negro (ACN, I954-I976), ocupando espaços interessantes e propositivos, entre i 958 e I964. Junto deles, no entanto, e orbitando o universo da ACN, localizam-se outros sujeitos como Sergio Milliet, Paula Beiguelman, Octavio Ianni, em momentos e condições distintas de aproximação. E de maneira mais intensa, na fase final da Associação, a figura pouco estudada de Eduardo de Oliveira e Oliveira (I923-I980), sociólogo negro, igualmente ligado ao grupo uspiano e que assumiu a direção da ACN.

Tais relações se configuraram em presença em atos públicos, representações autorizadas para falar em nome do coletivo negro, participação em eventos registrados pela imprensa. Ou mesmo adesão à associação, com fichas de filiação, distinguindo-se como "sócio" ou "sócio honorário", configurando também o pagamento de mensalidade. Ou, em caso mais explícito, assumindo a direção da associação, responsabilizando-se por sua condução. As informações e apresentações de documentos que tratam dessas relações específicas são inéditas na bibliografia do pensamento social sobre o tema ou da fortuna crítica de Fernandes (D’Incao, I987; Arruda, 200I; Sereza, 2005; Campos, 2014), constituindo-se em dados coletados especificamente a partir do estudo da Associação Cultural do Negro, que tenho desenvolvido recentemente. ${ }^{\mathrm{I}}$ Acredito que isso permita perspectivar a participação e o protagonismo antirracista de intelectuais e ativistas negros na história do pensamento social.

\section{OS CAMPEÕES DA REFORMA: INTELECTUAIS NEGROS E SOCIÓLOGOS EM TEMPOS DE MUDANÇA SOCIAL}

Ao defender em I964 A integração do negro na sociedade de classes como tese de cátedra, Fernandes já havia tido diferentes experiências de contato e investigação com movimentos sociais no meio negro, na pesquisa anterior empreendida com Roger Bastide. Argumentei em outro trabalho (Silva, 2013) que isso seria fundamental para a construção daquela obra. Sinais de tal importância são perceptíveis nas citações feitas ao longo do texto, mas também, de partida, nos agradecimentos que o autor fez a figuras distintas, na abertura do trabalho de I964, e nos agradecimentos de Bastide e Fernandes em I955, como seguem:

ao secretário da Comissão para o Estudo das Relações Raciais entre Negros e Brancos em S. Paulo, Jorge Prado Teixeira, que foi também colaborador nas pesquisas ecológicas.[...] às diversas associações de negros em S. Paulo: Associação José do Patrocínio de S. Paulo, Irmandade de N.S. Rosário dos Homens Pretos, a Legião Negra de S. Paulo; aos informantes de côr, drs. Raul Joviano do Amaral, 
Edgar Santana, Arlindo Veiga dos Santos, Francisco Lucrécio, Geraldo de Paulo e Ângelo Abaitaguara, e aos srs. José Correia Leite, Geraldo Campos de Oliveira, Francisco Morais, Luis Lobato, professor Antonio Dias, José Pelegrini, Vicente de Paula Custódio, Paulo Luz, Vitalino B. Silva, Mário Vaz Costa, Carlos Assunção, Romeu Oliveira Pinho, Joaquim Valentim, Nestor Borges, Cirineu Góis, José de Assis Barbosa, Adélio Silveira, Anibal de Oliveira, Luis Aguiar, Benedito Custódio de Almeida, Gil de Carvalho, José Inácio do Rosário, Sofia de Campos, Aparecida Camargo, Nair Pinheiro, e sras. Benedita Vaz Costa, Maria de Lourdes Rosário, Maria Helena Barbosa, Ruth de Souza e Nilza de Vasconcelos (Bastide \& Fernandes, 2008)

A essa lista gostaria de agregar novos agradecimentos. Primeiro, ao Dr. Roger Bastide, que me levou a estudar sociologicamente as relações raciais em São Paulo [...] Segundo, aos senhores José Correia Leite, Raul Joviano do Amaral e Henrique Cunha, pela prestimosa colaboração que nos deram, colocando à nossa disposição os exemplares existentes de jornais que circularam ou ainda circulam no "meio negro" de São Paulo. Pedimos vênia para prestar uma homenagem a Jorge Prado Teixeira, um colaborador inestimável e um infatigável batalhador pela causa do negro, que infelizmente foi roubado ao círculo dos vivos (Fernandes, 1978a).

Fernandes (1977) reforçaria em outro texto, "Em busca de uma sociologia crítica e militante", publicado em A sociologia no Brasil, que aspectos das suas pesquisas anteriores, sobre as troças no Bom Retiro e o culto a João de Camargo em Sorocaba, o haviam aproximado das várias cidades dentro da cidade e o mundo negro, sob orientação de Bastide. Igualmente a sua socialização primária como morador de cortiços, pobre, tendo de se medir com a vida desde a infância teria, em sua visão, lhe permitido conhecer a experiência de ser um negro em São Paulo, no final dos anos I920 e ao longo da década seguinte. Experiências de discriminação e preconceito do ângulo da pobreza, instrução prejudicada e da origem estigmatizada (filho de mãe solteira) que se aproximariam do pugilo de homens e mulheres negros na mesma época.

Fato é que os nomes citados pelos autores em seus agradecimentos e recordações não são aleatórios, mesmo que a maioria seja de desconhecidos ou de difícil rastreamento nos dias correntes. E é necessário promover, agora, uma rotação de perspectivas - da obra e da figura do sociólogo para seus sujeitos pesquisados - para entender qual a importância da presença desses intelectuais e ativistas negros em suas pesquisas e no cenário posterior. Estão ali representantes da imprensa, da Frente Negra Brasileira, de batalhões da Legião Negra de I932, das associações mencionadas explicitamente e também da Associação Cultural do Negro, que reúne vários desses ativistas a partir de I954. Jorge Prado Teixeira, por exemplo, foi o responsável por aproximar os ativistas e intelectuais negros dos sociólogos uspianos. Fontes ainda não devidamente checadas o apontam como aluno da Faculdade Filosofia, Ciências e Letras da USP, no curso de Ciências Sociais. O estudante de Ribeirão Preto, no entanto, foi um dos assinantes da ata inaugural, registrada em cartório, da Associação Cultural do Negro, 
em dezembro de 1956. Ele também pertenceu à Associação José do Patrocínio, coletivo negro para homens e mulheres, criado em I947, visando à instrução para adultos e assistência, onde também militava Raul Joviano do Amaral.

Amaral, também com fontes não checadas junto à instituição, foi estudante da Escola Livre de Sociologia e Política, nos cursos de Estatística e Sociologia. Antes disso, Joviano já era militante do movimento negro, pelo menos desde a década de I930, como partícipe da Frente Negra Brasileira, de jornais da imprensa negra paulista e da Irmandade do Rosário dos Homens Pretos de São Paulo, instituição sobre a qual ele escreveu um importante livro, Os pretos do Rosário de São Paulo (Amaral, I99I). Joviano também era advogado, com escritório no Centro da cidade, tendo tido certo papel num caso de crime envolvendo racismo, como o caso do Restaurante Chinês, segundo Bóris Fausto (2009: I 29-I 30). E no intervalo democrático inaugurado com o fim do Estado Novo (I937-I945), ele se lançou, como Abdias do Nascimento, Sofia de Campos e outros sujeitos negros, candidato a cargos políticos em São Paulo, configurando um momento importante da participação negra em formulação de projetos para o seu grupo social (Sotero, 20I5; Rios, 20I4).

Nomes como os de José Correia Leite, Henrique Cunha, Geraldo Campos de Oliveira, José Inácio do Rosário, José Pellegrini também não devem passar despercebidos desses agradecimentos, tanto em Integração do negro como em Brancos e negros em São Paulo. São todos homens e mulheres negros que pugilaram pela causa antirracista desde o começo do século XX. Todos eles foram informantes da pesquisa Unesco. Alguns demandavam ainda mais, como Edgar de Santana, em ser um pesquisador das investigações ou José Correia Leite, que escreveu uma monografia a partir de sua história de vida, coletada por Renato Jardim Moreira (um dos assistentes de Bastide e Fernandes). Todos eles foram sujeitos fundamentais para fornecer os dados e histórias de vida da experiência cotidiana da discriminação utilizados em Brancos e negros em São Paulo e Integração do negro na sociedade de classes. E, ouso pensar, por aproximar e corporificar o debate teórico acerca de preconceito e discriminação racial dos sociólogos das experiências e cenários concretos dos negros na cidade de São Paulo ou de suas trajetórias pregressas, em outras cidades do interior e estados brasileiros. Por outro lado, como nota Viviane Angélica da Silva (2015: 82), é importante assinalar esses momentos de fricção entre ativistas e intelectuais negros (como os citados) e a equipe de sociólogos uspianos (e mesmo entre os próprios sociólogos, lembrando a trajetória de Virgínia Leone Bicudo na pesquisa), para não conferir excessivo peso a uma aliança política que se dava também em condições de dessemelhanças (Silva, 20I5: 82).

Importa, entretanto, o encontro na encruzilhada do social e suas circunstâncias. O que os sociólogos queriam? Pelo que os ativistas e intelectuais negros lutavam? Como se dão essas relações? O interregno I945-1963, embora democrático, recoloca os negros, outrora associados, numa posição de que tudo ainda 
estava por fazer. Em São Paulo, suas ações desde o início do século XX organizavam-se no sentido de criar formas de solidariedade e coesão internas, capazes de integrar frações do grupo num ideal socialmente compartilhado, por meio da imprensa e das associações, visando à luta contra o preconceito racial. Todavia, o que se passa com as ciências sociais, em São Paulo? A sociologia estava na outra margem do caminho: a discussão crítica das relações raciais não era priorizada sistematicamente pela maioria das teses do momento. A encruzilhada, portanto, é a cidadania republicana e os seus impeditivos para, falando com Florestan Fernandes (I978b: 463), “forjar nos trópicos este suporte de civilização moderna”. Para os negros associados, denunciar o após Abolição e o preconceito velado cotidiano, bem como a inépcia do Estado em combater a discriminação, apesar da edição da Lei Afonso Arinos em I95I. Seriam eles por eles, organizando-se autonomamente. Se possível, com alianças de intelectuais como os sociólogos, na construção de uma verdadeira democracia. Destarte, há um encontro fecundo, polêmico e que possui consequências que nos interessam aqui.

Fernandes qualificou esses esforços do associativismo político e intelectual negro de São Paulo de reformismo social, em Integração do negro na sociedade de classes. Tratava-se de esforços empreendidos por aqueles ativistas e intelectuais em simultaneamente denunciar o preconceito e a discriminação, atacando radicalmente o mito da democracia racial, sendo que, com isso, também procuravam organizar-se coletivamente, emancipando-se. Ao emancipar o negro e combater o racismo, visavam, por outro lado, modificar os brancos. Os negros lutavam duplamente e por dois sujeitos ao mesmo tempo, tentando reformar os fundamentos da ordem social competitiva, instaurada na desigualdade de condições, operando como campeões da "revolução dentro da ordem" (Fernandes, I978b:Io), portanto, heroicamente se propondo a ser reformadores da nova ordem social.

Tratava-se de tarefa hercúlea, feita no cenário de uma sociedade fechada à mudança democrática das circunstâncias. A quaisquer sinais mais radicais de transformação, a ordem social e política responderia com violência, discriminação e repressão - como ocorre em I964. Acredito que esse diagnóstico do reformismo, de certa maneira moderado, dos movimentos sociais no meio negro também pode ser pensado para a situação política dos cientistas sociais que dele se aproximaram. O tema da mudança social estava nos seus horizontes, em diferentes arenas, para diagnóstico e atuação, como foi apontado de maneira precisa por Elide Rugai Bastos (2002: 1 83-230). O acesso à educação pública, os debates acerca da expansão pública do ensino superior, discussões sobre o preconceito e discriminação raciais, as condições de vida nas cidades em franco processo de metropolização e industrialização, os direitos trabalhistas nos mundos citadino e rural; e, por fim, a possibilidade de transformações democráticas da vida política e social brasileira são temas enfrentados por esse conjunto de cientistas sociais, explicitados na série de artigos publicados em Mudanças sociais no Brasil (Fernandes, 2008) e A sociologia numa era de revolução social (Fernandes, I976), com a síntese no prefácio de I962: 
São muitos os problemas com que se defronta o sociólogo numa situação histórico-social como a que prevalece no Brasil e nos demais países subdesenvolvidos [...] Ninguém consegue isolamento para concentrar-se sobre seus planos de investigação [...] Algo, entretanto, dá sentido criador a esse mecanismo de uso (sob muitos aspectos de mau uso) do talento pela sociedade. Ele arranca o sociólogo do "gabinete", integrando-o nos processos de mudança social, fazendo-o sentir-se como alguém que possui o que dizer e que, eventualmente, poderá ser ouvido [...] Enfim, a sociedade, que não lhe pode conferir sossego e segurança, coloca-o numa posição que o projeta no âmago dos grandes processos históricos em efervescência (Fernandes, I976: I5-16).

Não haverá novidade em repisar os argumentos expressos nesses livros. Importa aproximação de contextos sociais e políticos em que o mundo do(s) sociólogo(s) e o dos intelectuais e ativistas negros passam a se encontrar ainda mais, com sentidos políticos talvez em processo de aliança e reconhecimento, permitindo, por exemplo, a realização do diagnóstico expresso na citação anterior.

\section{ÓRBITAS SINCRÔNICAS, COM ALGUMA COLISÃO}

Voltemos à Associação Cultural do Negro. Ela foi fundada em I954, por um conjunto de intelectuais e ativistas negros, homens majoritariamente interessados em criar uma associação que representasse o negro na sua ausência das comemorações do quarto centenário da cidade de São Paulo, naquele ano. Seus estatutos foram definidos em I956, e ela passa a funcionar, a partir de então e até I965, no I60 andar do Edifício Martinelli, no Centro de São Paulo, procurando atuar no espaço público com a valorização da memória negra e da luta antirracista contemporânea. Jornais (Mutirão, Níger), cadernos de publicações (Série Cultura Negra), coletivo de teatro (Teatro Experimental do Negro de São Paulo), homenagens, recitais, atos e protestos públicos, correspondências etc., tudo isso se encontrava no seu escopo de atividades, especialmente na fase de I956 a I964 (Silva, 2012; 2013).

Considerando seus fundadores - José de Assis Barbosa, Jorge Prado Teixeira, José Correia Leite, Geraldo Campos de Oliveira, entre outros - e suas experiências pregressas, bem como as relações já expostas, é compreensível encontrar nos arquivos da ACN, durante a pesquisa que tenho empreendido sobre a história da associação, documentos que expressam a relação abaixo:

São Paulo, Brasil, 29 de agosto de 1962

A Diretoria Cultural da Associação Cultural do Negro do Estado de São Paulo Brasil, tem o imenso prazer de apresentar o ilustre Professor FLORESTAN FERNANDES, como representante de nossa entidade, para fins culturais, junto a entidades e pessôas [sic] interessadas em tratar de assuntos ligados a finalidades culturais desta Associação.

Antecipadamente gratos. ${ }^{2}$ 
Como o sociólogo ganhou essa distinção? Quais as relações estabelecidas entre ele e seus sujeitos de pesquisa que permitiram que ele fosse alçado à condição de representante autorizado da ACN? Infelizmente, o documento não menciona a quem se destina. Contudo, sua natureza genérica permite inferir que se trata da possibilidade de Fernandes ser o mediador dos intelectuais e ativistas negros em espaços que talvez eles não pudessem facilmente acessar. Ou o uso interessado, pelos intelectuais negros, do prestígio e distinção acadêmicos já alcançados naquele momento pelo autor, para os fins e interesses em prol da ACN. Prestígio esse alicerçado nos dados fornecidos por aqueles intelectuais e ativistas negros em pesquisas anteriores. Uma relação de simbiose política, talvez.

Por exemplo, em 1956, quando a ACN organiza a I Convenção Paulista do Negro na cidade de São Paulo, é possível flagrar entre os membros convidados a palestrar e/ou apoiar a atividade os nomes de cientistas sociais uspianos, diretamente ligados às pesquisas sobre os negros paulistas: entre os membros das comissões técnicas, naquela denominada "Problemas Econômicos e Relações Raciais", encontra-se Renato Jardim Moreira ${ }^{3}$ - assistente e orientando de pesquisa de Bastide e Fernandes nos estudos sobre relações raciais (junto de Fernando Henrique Cardoso e Octavio Ianni). E na "Relação dos Convencionais Inscritos até de I 6 de maio de I956" o sétimo nome é o de Florestan Fernandes. ${ }^{4}$

No Relatório da Diretoria Executiva (de Io de setembro de I957 a 3I de julho de I958) existem pistas sobre esse cenário, incluídas aquelas sobre a produção dos argumentos de uma das obras mais importantes das ciências sociais brasileiras. No documento de oito folhas, a diretoria executiva, presidida por José Correia Leite, informa os sócios sobre as atividades culturais, sociais, políticas e problemas da associação: a comemoração da Lei do Ventre Livre (28 de setembro) e homenagem pública a José do Patrocínio; o protesto organizado pela ACN em São Paulo contra o prefeito de Little Rock, Arkansas (EUA), que havia decidido impedir a frequência de estudantes negros a uma escola secundária da cidade; a organização de uma "Noite de Poesia" em homenagem a Cruz e Souza; a recepção ao trumpetista estadunidense Louis Armstrong, quando de sua visita a São Paulo; informes financeiros e de atos punitivos a associados; as comemorações do Ano 70 da Abolição (sobre este último ponto, ver Silva, 20I 2).

A respeito do denominado Ano 70 da Abolição, são detalhadas atividades organizadas e acontecidas para a efeméride, que seguiram de fevereiro a maio de I958, com a participação de intelectuais e artistas como Sergio Milliet, Clóvis Garcia, Henrique Losinkas Alves, Abdias Nascimento, Rossini Tavares de Lima, Édison Carneiro, entre outros. Também está nesse rol a seguinte:

Dia 29 de maio - Conferência do Professor Florestan Fernandes, catedrático de Sociologia da Faculdade de Filosofia, Ciências e Letras da Universidade de São Paulo, na Biblioteca Municipal, subordinada ao tema "A integração do negro na sociedade brasileira". ${ }^{5}$ 
Isso é deveras interessante. Em I958, Fernandes, no rol de atividades organizadas pela Associação Cultural do Negro para os debates e comemorações do Ano 70 da Abolição, apresenta uma conferência acerca da pesquisa em andamento que ele finalizaria tão somente em março de I964. Essa perspectiva, de um trabalho em andamento e em diálogo, se fortalece ao observar também no acervo da ACN, dois comunicados que tinham a finalidade de ser distribuídos aos jornais, em maio de I960, para atividades relativas ao debate sobre os sentidos da Abolição:

Comemorações Abolicionistas de 1960

Da programação cultural consta a realização da conferência a ser proferida pelo professor Florestan Fernandes, na Biblioteca Municipal e o espetáculo que o Teatro Experimental do Negro de São Paulo organizou especialmente para as comemorações patrocinadas pela Associação Cultural do Negro. ${ }^{6}$

Esse primeiro comunicado, a respeito da conferência de Fernandes, é datado de 3 de maio de I96o. O segundo, mais extenso, refere-se a I 6 de maio de 1960 e dirige-se ao senhor Sílvio Vasconcelos, então presidente do Sindicato dos Empregados no Comércio de São Paulo:

Senhor Presidente

Dentre as atividades programadas destacasse[sic]a conferência a ser proferida pelo ilustre professor Octavio Ianni, da Faculdade de Filosofia Ciências e Letras da Universidade de São Paulo, no próximo dia 27 do corrente.

Desejando merecer a valiosa colaboração dessa nobre entidade classista, vimos solicitar pela presente a cessão a título gracioso do auditório da mesma, a fim de que nele possa ser realizada referida conferência, que se subordina ao tema "O negro no Brasil Meridional".?

Essa segunda nota é particularmente interessante. "A título gracioso", o auditório seria cedido ao sociólogo para que ele falasse sobre sua pesquisa, em processo de realização, acerca dos negros nos estados do Sul, em particular o Paraná. Pesquisa supervisionada por Fernandes, dividida com Fernando Henrique Cardoso e que seria publicada em I 962 com o título As metamorfoses do escravo: apogeu e crise da escravatura no Brasil meridional. Se o pedido para que Ianni fizesse a conferência no auditório gratuitamente cedido deu certo ou não é menos importante que o fato em si. Trata-se de um dado importante acerca da aproximação dos sentidos entre sociólogos e movimentos sociais no meio negro, mediado pela Associação Cultural do Negro.

Além disso, é igualmente interessante analisar os espaços sociais em que essas conferências deveriam ser pronunciadas. Bibliotecas públicas, sindicatos de entidades de classe: fora do ambiente universitário, voltadas para audiência interessada. Talvez com um esforço de aproximação de linguagem, sem perder o rigor, para um público mais amplo. Esforço esse que compõe um certo aspecto dessa geração de cientistas sociais, num momento de intensa 
luta por mudança social e que é narrado de maneira particularmente instigada por Fernandes (1976) no prefácio que escreve à primeira edição de A sociologia numa era de revolução social, em I962. Creio que a exposição desses argumentos qualifique a apresentação do documento a seguir:

\section{Sâ. Faulo, 25 de Mexp̧ to 2965}

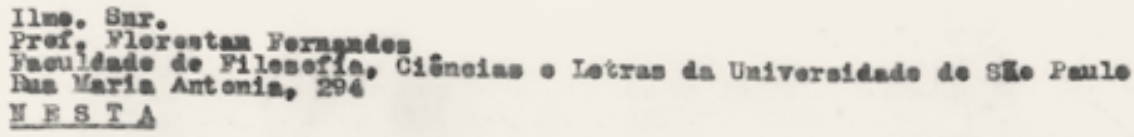

\section{Prefessôx:}

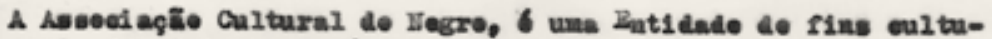
raile, ae ponte de vista see1016gleo, procurando ceagreger as manifos-

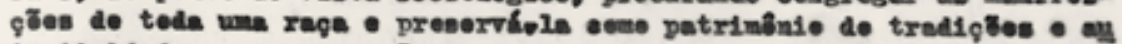

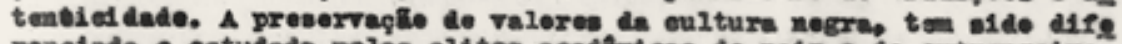
reneiada - estudade pelas elites acadbileas do pais o ce axtrangeire,

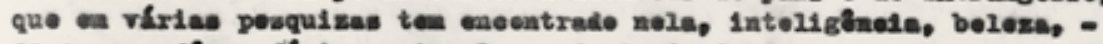

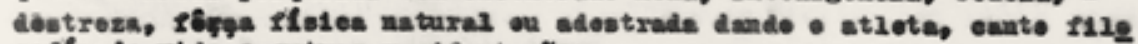

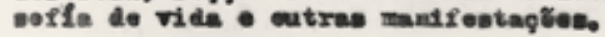

Considerandes a monumentel obre apresentada per Vosse senho-

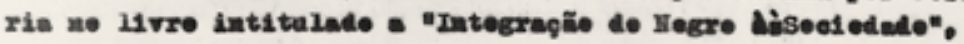

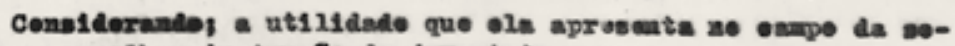
elelegia para melhor instrugile da furvatude, Consilerence alnda, a entiga - prefunds aniade que the dere tamoe,

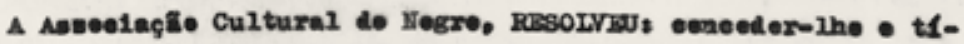

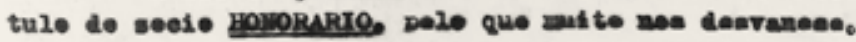

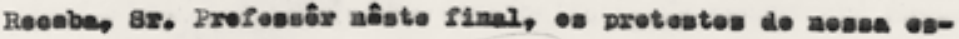
pooial eatian e conv1doragio.

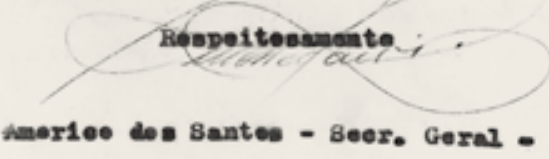

Documento I

Concessão de Título de Sócio Honorário da Associação

Cultural do Negro a Florestan Fernandes, março de $1965^{8}$ 
As fontes do arquivo e mesmo a fortuna crítica de Fernandes não permitem afirmar se ele aceitou o título. Mas também esta informação - a concessão da honraria - salvo engano, até o momento, era desconhecida. O que importa, mais uma vez, é menos a eficácia que o sentido concreto e simbólico da ação. A integração do negro na sociedade de classes, tese de cátedra apresentada um ano antes pelo sociólogo, com repercussão fora do ambiente universitário e ao encontro de uma representação de movimento social no meio negro aquele cujos integrantes ou uma parcela deles haviam participado da Pesquisa Unesco de Relações Raciais em São Paulo e fornecido as informações necessárias para tornar possíveis os trabalhos dos sociólogos. Especialmente no segundo volume de Integração - No limiar de uma nova era - as interpretações do sociólogo são absolutamente alicerçadas nas informações recebidas de seus interlocutores, para discorrer sobre "Os movimentos sociais no meio negro". Isso é um dado nada menosprezível.

Também importa destacar o ano. Ruim politicamente em todos os sentidos progressistas. Momento em que a ACN passa por fase de dificuldades, levando a mudança em seu quadro associativo, do local de sua sede e mesmo de direção, e cujos aspectos não serão abordados neste artigo. Igualmente turbulento, entretanto, para a sociologia uspiana, pelas mudanças institucionais que o golpe de Estado civil-militar provocaria no ambiente político e científico da Faculdade de Filosofia e das Ciências Sociais no Brasil (Sereza, 2005; Martins, I 998: 44-45; Velho, I983: 24I-242).

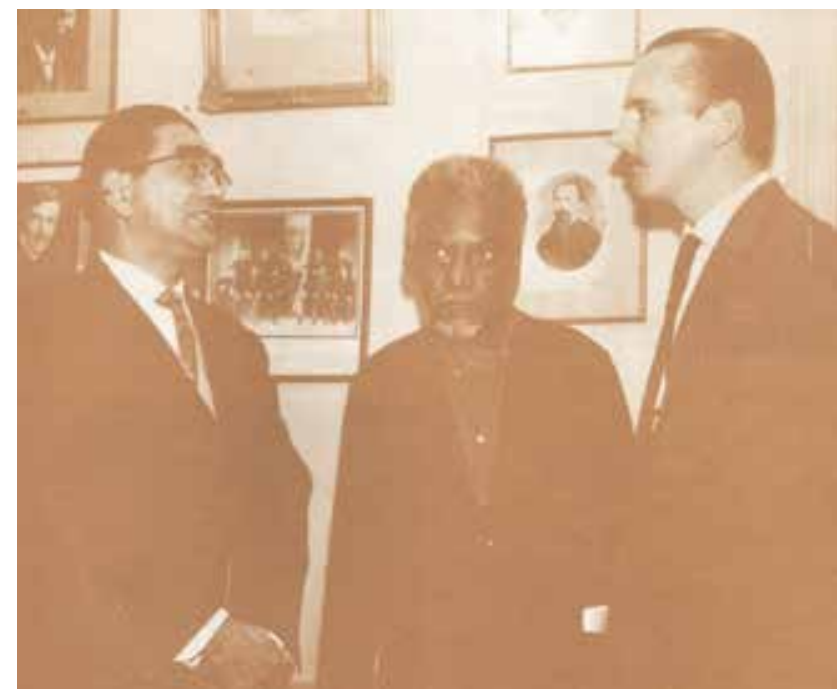

Florestan Fernandes, Solano Trindade e Henrique Losinkas Alves, na sede da ACN, s.d. Fonte: Alves, I989. 


\section{MUDANÇAS DE RUMOS}

As dificuldades políticas após o golpe de Estado civil-militar impõem reconversões de lugares sociais para sociólogos e movimentos negros. No primeiro grupo, especialmente para os que estão no círculo de Fernandes, implica prisões, exílios e perda de prestígio universitário. No caso dos negros, observando o caso da ACN, se eles não saem de cena, se reconfiguram em outros espaços e formas de ativismo, uma vez que se mudam da sede do Edifício Martinelli para o bairro Casa Verde. E alguns de seus membros são atingidos pelo golpe, forçados ao exílio, a sair de cena mais explicitamente (Kössling, 2007; Silva, 20I2). Ou mesmo, dada a idade avançada dos membros do conselho diretor da associação, pessoas sexagenárias decidem se aposentar do trabalho mundano e se distanciar do ativismo político (Leite \& Cuti, I992).

Essa é fase ainda nebulosa da vida associativa negra em São Paulo, observada pela ACN. O que importa, no entanto, é que ela não desaparece. Se o intervalo de ações ocorridas entre I965 e I976 ainda é constituído de lacunas, não é menos importante saber que um sociólogo negro assumirá essa segunda fase e que ele orbitava o grupo de pesquisadores ligados a Florestan Fernandes. Não se trata de continuidade de fácil traçado, dada a dificuldade de coleta de dados, mas vale esboçar alguns argumentos.

Eduardo de Oliveira e Oliveira, junto da advogada branca Gilcéria de Oliveira, será responsável pela fase da Casa Verde na vida associativa da ACN. Destaco os marcadores de Gilcéria pelo fato de serem incomuns na trajetória diretiva da associação: mulher e branca, algo inédito. Oliveira e Oliveira tem importância ainda não pesquisada a contento nesses anos $1970^{9}$ do movimento negro (Alberti \& Pereira, 2007), mas suscitada em memórias de cientistas sociais ou novos ativistas do movimento negro daquele momento como alguém com destaque, tanto pela organização da Quinzena do Negro da USP (em I977), pela escrita e apresentação da peça de teatro E agora falamos nós (I97I-I973), em parceria com a ativista e intelectual negra Thereza Santos, à época responsável pelo Centro de Cultura e Arte Negra - Cecan. É o que também recorda um colega de geração de Oliveira e Oliveira, da época de formação em ciências sociais no grupo uspiano:

Foi de minha turma e foi meu amigo Eduardo de Oliveira e Oliveira, intelectual refinado e culto, mulato, dos meus conhecidos e amigos o que melhor compreendia as gradações e as implicações da diferenciação social naquele estranho e fascinante mundo da Faculdade de Filosofia da rua Maria Antônia, perto da qual morava. Ele era filho de um estivador negro do porto do Rio de Janeiro, que se tornara líder sindical e, como ele mesmo dizia, pelego do trabalhismo de Vargas. Eduardo tivera a melhor educação que alguém podia receber em sua época no Rio de Janeiro. De vez em quando, seu pai embarcava-o na limusine de seu uso e dava um passeio pelas docas, mostrava-lhe os estivadores que carregavam nas costas pesada sacaria e lhe fazia esta advertência: "Não se esqueça nunca de que o que você é e virá a ser deve a essa negrada”. Eduardo não esqueceu. De vez em 
quando convidava seus amigos negros e vários de nós, que vínhamos "de baixo", e também alguns professores, artistas e intelectuais para uma mesa de queijos e vinhos finos em seu apartamento para, no estilo das velhas famílias, um sarau de conversação culta. Organizou para negros do bairro da Casa Verde uma escola, para a qual convidava professores da USP, com razão convencido da função emancipadora dessa ressocialização. Escreveu uma peça teatral emblemática, a cuja estreia compareci, sobre as contradições e as armadilhas da ascensão social no meio negro - E, agora, falamos nós -, dirigida e apresentada no Teatro do Masp por sua amiga Teresa Santos, a atriz. O título da peça foi inspirado num incidente ocorrido, que presenciei, no prédio de Filosofia e Ciências Sociais, na Cidade Universitária. Eduardo organizara um seminário sobre o negro, numa das salas, para o qual convidara vários professores da Faculdade de Filosofia e vários negros. Uma das professoras, ao terminar sua exposição, que foi a primeira, explicou que precisava se retirar, pois tinha outro compromisso. Ela já estava na soleira da porta quando Eduardo pediu-lhe que voltasse, pois tinha algo importante a dizer. E disse mais ou menos o seguinte: "Nós (negros) passamos séculos ouvindo vocês. Quando chega a hora de falarmos, vocês dizem que não têm tempo para nos ouvir". Ela ficou muito embaraçada com a interpelação inesperada, desculpou-se, disse que não era nada daquilo e foi embora (Castro, 2010: 239-240).

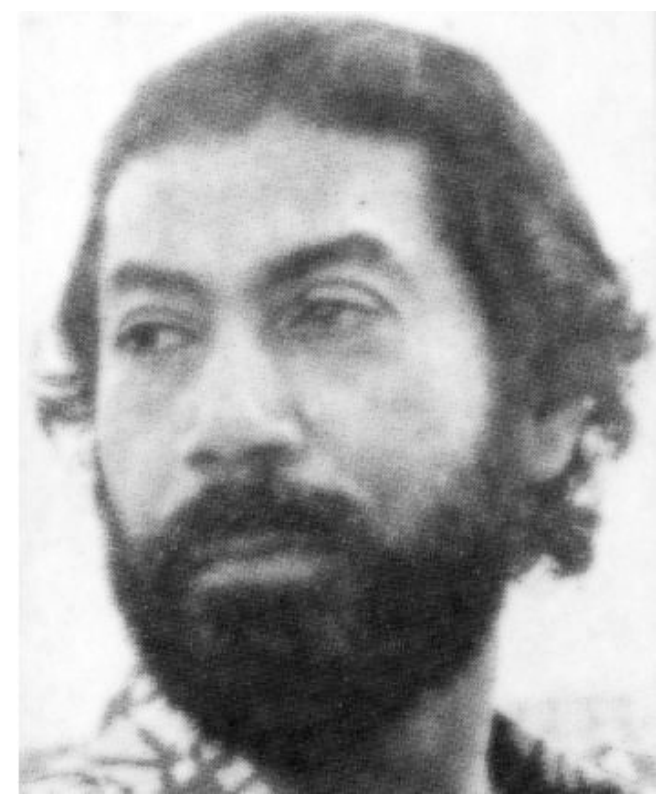

Eduardo de Oliveira e Oliveira, s.d.

Fonte: Acervo UEIM-UFSCar.

Catálogo da Coleção Eduardo de Oliveira e Oliveira, UEIM-UFSCar, I984. 
A escola a que José de Souza Martins (Castro, 20ı) se refere é a transferência da sede da ACN para a Casa Verde. Nessa fase, a mudança de sede levou a uma alteração geográfica e também a uma mudança de perfil de atuação. $\mathrm{Na}$ rua Jaboatão ensinava-se em cursos de alfabetização, reforço em matemática, geografia, ciências e português. Ou cursos de história geral e brasileira, e cultura afro-brasileira e africana, ministrados por Oliveira e Oliveira.

Nessa fase, que se dá entre ig66 e I976, haverá algo ainda para se explorar, em matéria de pesquisa, em relação à presença de sociólogos, daquele grupo próximo a Fernandes, na Associação. Os movimentos dos dois grupos, cientistas sociais e ativistas negros, são então mais sinuosos e menos sincrônicos do que em fases anteriores. Não tenho, por enquanto, respostas mais precisas sobre o motivo de certas fichas de filiação e/ou contribuições se encontrarem nos arquivos da ACN, nessa fase. Isso se deverá sem dúvida à presença de Eduardo de Oliveira e Oliveira e ao fato de ele circular entre dois mundos, promovendo a conexão entre o ambiente universitário e esse associativismo negro. Mas também às disposições políticas e culturais contraídas em momentos anteriores, explicitadas antes, que corroboram as afirmações de Martins e algumas de minhas hipóteses. Vejam-se, exemplarmente:
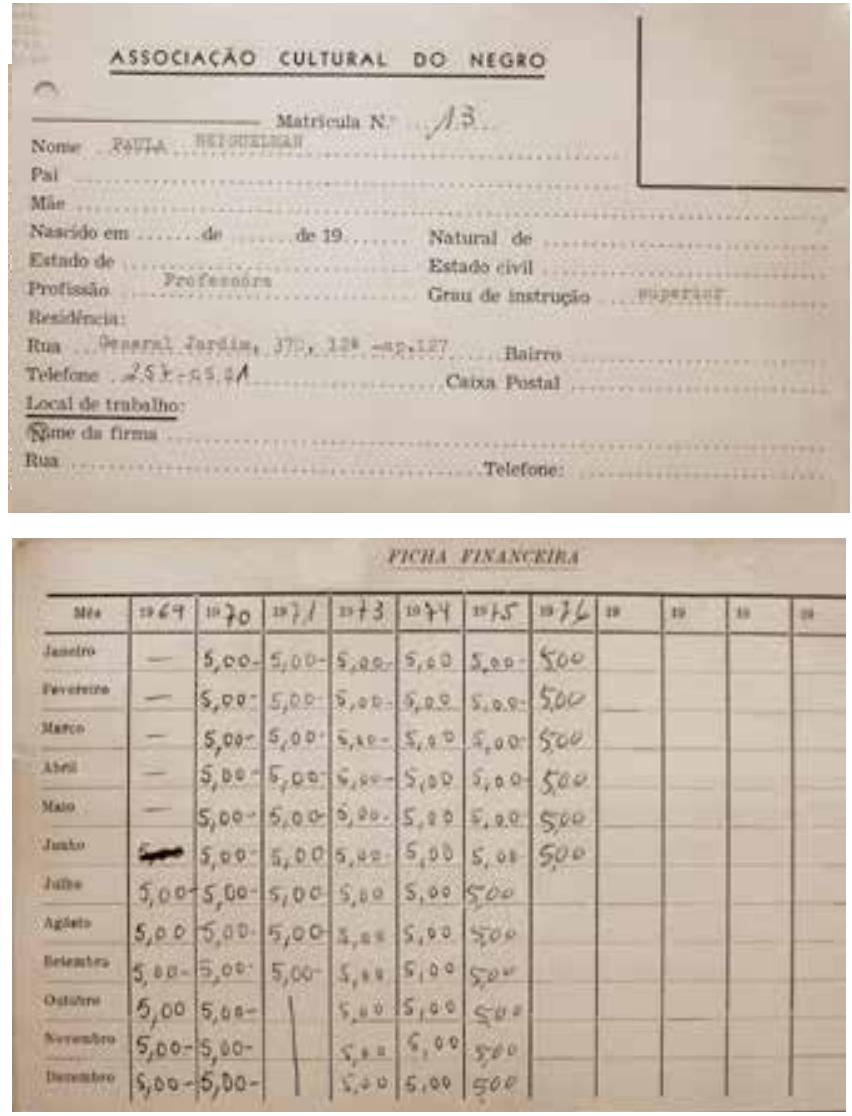

Documento $2 \mathrm{a}$ e $2 \mathrm{~b}$

Ficha de filiação e contribuições entre 1969 e 1976 da cientista social Paula Beiguelman à ACN 
ARTIGO | MÁRIO AUGUSTO MEDEIROS DA SILVA

I 23

ASSOCIACAO CULTURAL DO NEGRO

São Paulo - Brasil

PROPOSTA

MATRICULA N.

Nome Citavio la MMi

Nascidoem 13 de cathbro de nó6 na Cidade de / tú FUNDADA EM 28-12-54 Estado de ST Tanto Estadocivil Caledo Pai Andte laweí

Filiaçâo:

Mie Aue Guarigtie larim:

Protissáo fuftonl Sociologo Documentos $17 \mathrm{G} 1.214 .005$

Grä de instrusao eviversctario

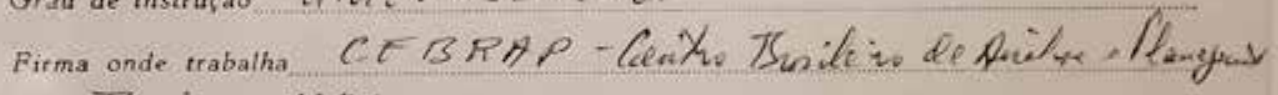

Rua Ifaic 499 Bairo

Tel.

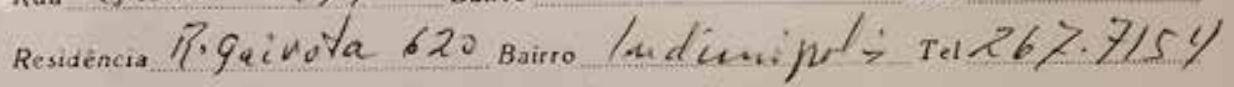

Onde deve ser cobrado R. Goivoto, 620

O proposto

O proponente

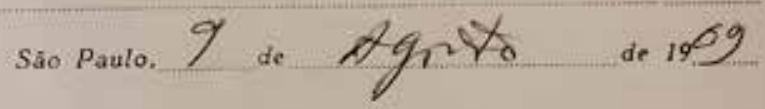

Observaçōes

Coupramads

filúg, veng

Documento 3

Proposta de filiação de Octavio Ianni

à Associação Cultural do Negro, em I969 
Além das fichas e propostas de Beiguelman e Ianni, nessa fase encontram-se ainda propostas e documentos de contribuição financeira endossados pelo cientista social Ruy Coelho, por artistas como Carlos da Silva Prado e Aldemir Martins ou pelo industrial e bibliófilo José Mindlin. A esse respeito, é interessante ponderar sobre o que me informou, em entrevista, a ex-presidente da Associação Gilcéria de Oliveira, que centraliza o papel desempenhado por Eduardo de Oliveira e Oliveira nessa fase:

[Eduardo de Oliveira e Oliveira] era considerado um intelectual, de primeira linha. Valorizado por ser um intelectual como os intelectuais da USP. Marilena Chaui, a Paula Beiguelman, o Antonio Candido, Florestan Fernandes, aquele pintor famoso Aldemir Martins colaboravam com a Associação. Todo esse povo colaborava, pagava uma quantia mensal para manter. Nós não tínhamos verba oficial. E todo esse povo foi arrebanhado pelo Eduardo. Ele também era muito amigo de uma professora da USP, doutora Paula Beiguelman, era amicíssima dele, e o tratava muito bem e tal. O Mindlin era muito amigo do Eduardo. O Eduardo tinha acesso ao Mindlin com a maior facilidade. Financeiramente, quem garantiu o funcionamento da Associação foi o Eduardo. Porque ele era ligado a este pessoal, idealista, que tinha dinheiro e que financiava. Eles pagavam por mês. ${ }^{\text {10 }}$

Ainda se trata de uma fase da ACN que carece de mais pesquisa, até sobre as mudanças de características - do autofinanciamento pelos associados negros à contribuição financeira de apoiadores não negros, por exemplo. Todavia, neste momento, o que importa problematizar é a relação com uma geração de cientistas sociais cujos posicionamentos políticos levaram à colaboração em níveis variados.

\section{UMA AGENDA DE PESQUISA ABERTA E INCONCLUSIVA, POR ENQUANTO}

Trata-se de um aspecto de momento de disposições democráticas que atravessam três décadas (dos anos I940 a I970), gerações de cientistas sociais, projetos de pesquisa, a centralidade de um problema político e sociológico - mudança social e relações raciais aliadas à luta antirracista e integracionista. Os movimentos de cientistas sociais e ativistas intelectuais negros encontram-se em simultânea mudança de rumo: por um lado, aquela geração de cientistas sociais - tomando Fernandes como ponto focal - será alijada de seu papel no campo de forças institucionais da universidade e da sociologia de então, descrevendo trajetórias marcadas por obstruções e alteração de aposta no sentido político das ações: são exemplares a impossibilidade de retorno de Fernandes e Ianni à USP, alocando-se na PUC-SP, ou, ainda, os balanços negativos da trajetória sociológica feitos por Fernandes ao longo dos anos I970, sua aposta no socialismo e engajamento político direto, vaticinados em passagens como esta: "pertenço a uma geração perdida, um conjunto de intelectuais que enfrentou seus papéis e, em sentido concreto, cumpriu suas tarefas. Mas nem por isso chegou a atingir os seus objetivos e a ver seu talento aproveitado pela sociedade" (Fernandes, I977: 213). 
Por outro lado, os ativistas e intelectuais negros se encontram num momento de transição geracional e política: a reconfiguração do papel da ACN nessa fase dos anos 1970 acontece em paralelo com o nascimento de novas organizações, como o Centro de Cultura e Arte Negra (Cecan, em I97I) ou as discussões, em diferentes níveis em São Paulo, articulados com outros movimentos em outros estados que culminariam em I 978 na criação do Movimento Negro Unificado Contra a Discriminação Racial (MNUCDR). Sugeri, em outro trabalho (Silva, 2013), que surge, nesse momento, uma nova geração de ativistas políticos e escritores, nascidos ao longo dos anos I950, cuja linha de transmissão com as gerações anteriores é, em grande parte dos casos, interrompida. No entanto, ainda seria possível rastrear alguns vínculos, com base na entrada de alguns desses ativistas no ambiente universitário, socializando-se com temas, discussões e enfrentamentos de época; a presença de antigos militantes e escritores no cenário social, criando interesse por obras e pelo passado recente do negro no Brasil; mais específica, a difusão cultural promovida pelo jornal Versus (I974-I979) e a seção "Afro-Latino-América", a partir de I977, além de publicações como Árvore das Palauras e Jornegro (editados no Cecan) ou a penetração das ideias e informações sobre o ativismo negro em outros países, notadamente nos EUA e nas revoltas anticoloniais africanas (Silva, 2013).

Mudanças na forma do ativismo e nos sujeitos envolvidos nessa nova configuração, atreladas às mudanças na universidade e no campo da sociologia, levaram a afastamentos e não colaboração direta dos novos ativistas e intelectuais negros com os sociólogos. Projetos e sujeitos passam a descrever movimentos paralelos, em novas rotas. Tudo isso, no entanto, ainda é uma agenda aberta de pesquisa e um capítulo da história da sociologia no Brasil e do ativismo político e cultural negro a ser explorado.

Procurei apresentar brevemente neste artigo algumas dessas possibilidades em aberto, a propósito de um dossiê analítico sobre Florestan Fernandes. Minha intenção foi argumentar no sentido de que, embora haja centralidade daquele sociólogo na discussão sobre o tema das relações sociais racializadas, entre os anos I950 e meados dos I960, é igualmente produtivo verificar uma espécie de "retrato de grupo", em que outros cientistas sociais compõem ações semelhantes com efeitos parecidos, em circunstâncias variadas. Um retrato com várias faces, algumas negras, e algo estilhaçado pelo tempo.

As fontes de arquivo que apresentei até aqui são inéditas e as julgo proveitosas para que se lancem novos questionamentos sobre o tema. Por exemplo, investigar com mais acuidade, no âmbito da história da sociologia e do pensamento social no Brasil, o papel dos sujeitos de pesquisa como interlocutores de trabalhos clássicos da área - como os ativistas e intelectuais negros; procurar discutir os interesses desses sujeitos de pesquisa, tanto quanto possível, no diálogo com os cientistas sociais; e, por fim, indagar sobre as condições sociais para a construção de um horizonte de possibilidades de ações políticas 
e culturais comuns, entre sociólogos e seus interlocutores. Poderiam ser outros: movimentos sociais no campo, ativistas pela educação, trabalhadores urbanos, ativistas dos direitos civis (mulheres, homossexuais etc.), na mesma época delineados. O caso dos intelectuais e ativistas negros, organizados, parece-me exemplar nesse sentido, para sugerir e promover, na área, uma rotação de perspectivas comumente miradas.

Recebido em 07/o9/I7 | Aprovado em I2/Io/I7

Mário Augusto Medeiros da Silva é doutor pela da Universidade Estadual de Campinas (Unicamp), onde atualmente é professor do Departamento de Sociologia do Instituto de Filosofia e Ciências Humanas. Publicou entre outros A descoberta do insólito: literatura negra e literatura periférica no Brasil (1960-2000) (2013). 


\section{NOTAS}

I Trata-se de minha pesquisa atual, que contou com o apoio da Fundação de Amparo à Pesquisa do Estado de São Paulo (Fapesp): Estudo de associativismo político e cultural negro: Associação Cultural do Negro (I954-I976). Disponível em <http://www.bv.fapesp.br/pt/auxilios/88552/ estudo-de-associativismo-politico-e-cultural-negro-asso ciacao-cultural-do-negro-I954-I976/>.Acesso em I/Io/20I7.

2 Documento ACN DIE (Documento de Informações Essenciais) COE I040 PoI5 Jo80. Fonte: Coleção Associação Cultural do Negro - Unidade Especial de Informação e Memória, Universidade Federal de São Carlos (UEIM-UFSCAR).

3 Documento ACN DIE CCPN DIV o026 P Joio. Fonte: Coleção Associação Cultural do Negro - UEIM-UFSCAR.

4 Documento ACN DIE CCPN DIV 0023 P JoIr. Fonte: Coleção Associação Cultural do Negro - UEIM-UFSCAR.

5 Documento ACN DIE COS COI 0337 Poo5 Jo75, fls.06-07. Fonte: Coleção Associação Cultural do Negro - UEIM-UFS CAR. Grifos meus.

6 Documento ACN DIE COE D74I PoI2 Jo6r. Fonte: Coleção Associação Cultural do Negro - UEIM-UFSCAR.

7 Documento ACN DIE COE D74I PoI2 Jo68. Fonte: Coleção Associação Cultural do Negro - UEIM-UFSCAR. Grifos meus

8 Documento ACN DIE COE 0940 PoI4 J073. Fonte: Coleção Associação Cultural do Negro - UEIM-UFSCAR.

9 O historiador Rafael Petry Trapp tem-se dedicado, em sua pesquisa de doutoramento na Universidade Federal Fluminense (UFF), ao estudo da trajetória e do pensamento político de Eduardo de Oliveira e Oliveira.

Io Entrevista com Gilcéria de Oliveira concedida a Mário Augusto Medeiros da Silva, em I7 de março de 20I6, em São Paulo. 


\section{REFERÊNCIAS BIBLIOGRÁFICAS}

Alves, Henrique Losinkas. (I989). Um agitador cultural. Edição do Autor.

Alberti, Verena \& Pereira, Amílcar Araújo (orgs.). (2007). Histórias do movimento negro no Brasil: depoimentos ao CPDOC. Rio de Janeiro: Pallas/CPDOC-FGV.

Amaral, Raul J. (I99I) [I954]. Os pretos do Rosário de São Paulo. $2^{\text {a }}$ ed. São Paulo: Scortecci.

Amaral, Raul J. (1978). Roger Bastide - no coração do negro. Revista do Instituto de Estudos Brasileiros, 20, São Paulo, p. I 26 - I 29 .

Arruda, Maria Arminda N. (200I). Florestan Fernandes e a sociologia de São Paulo. In: Metrópole e cultura: São Paulo no meio século XX. Bauru: Edusc.

Bastide, Roger. (I973). Estudos Afro-Brasileiros. São Paulo: Perspectiva.

Bastide, Roger \& Fernandes, Florestan. (2008) [1955]. Brancos e negros em São Paulo: ensaio sociológico sobre aspectos da formação, manifestações atuais e efeitos do preconceito de cor na sociedade paulistana. 3 ed. São Paulo: Global.

Bastos, Elide Rugai. (2002). Pensamento Social da Escola Sociológica Paulista. In: Miceli, Sergio (org.) O que ler na ciência social brasileira. São Paulo/Brasília: Sumaré/Anpocs/ Capes, p. I83-230.

Bicudo, Virgínia Leone. (2010). Atitudes raciais de pretos e mulatos em São Paulo: Editora Sociologia e Política.

Campos, Antônia J. Malta. (20I4). Interfaces entre sociologia e processo social: A integração do negro na sociedade de classes e a pesquisa Unesco em São Paulo. Dissertação de Mestrado. PPGS/Universidade Estadual de Campinas.

Cardoso, Fernando H. (2008). Uma pesquisa impactante. In: Bastide, Roger \& Fernandes, Florestan. Brancos e negros em São Paulo: ensaio sociológico sobre aspectos da formação, manifestações atuais e efeitos do preconceito de cor na sociedade paulistana. 3 ed. São Paulo: Global.

Castro, Conrado Pires de. (20ro). Luiz Pereira e sua circunstância: entrevista com José de Souza Martins. Tempo social, São Paulo, 22/I, p. 21 I-276. 
D'Incao, Maria Angela (org.). (I987). O saber militante: ensaios sobre Florestan Fernandes. São Paulo/Rio de Janeiro: Ed. Unesp/Paz e Terra.

Fausto, Boris. (2009). O crime do restaurante chinês: carnaval, futebol e justiça na São Paulo dos anos 30. São Paulo: Companhia das Letras.

Fernandes, Florestan (2008) [I960]. Mudanças sociais no Brasil. 4 ed. São Paulo: Global.

Fernandes, Florestan. (I978a) [1964] A integração do negro à sociedade de classes: o legado da raça branca. São Paulo: Ática (vol. I).

Fernandes, Florestan. (1978b) [1964]. A integração do negro à sociedade de classes: no limiar de uma nova era. São Paulo: Ática (vol. 2).

Fernandes, Florestan. (1977). A sociologia no Brasil: contribuição para o estudo de sua formação e desenvolvimento. Petrópolis: Vozes.

Fernandes, Florestan. (I976) [1962]. A sociologia numa era de revolução social. 2 ed. Rio de Janeiro: Zahar.

Gomes, Janaína D. (2013). Os segredos de Virgínia: estudos de atitudes raciais em São Paulo (I945-1955). Tese de Doutorado. PPGAS/Universidade de São Paulo.

Kössling, Karin S. (2007). As lutas antirracistas de afrodescendentes sob vigilância do DEOPS/SP (I964-I983). Dissertação de Mestrado. PPGHS/Universidade de São Paulo.

Leite, José Correia. \& Cuti. (I992). ...E disse o velho militante José Correia Leite. São Paulo: Secretaria de Estado da Cultura.

Maio, Marcos Chor. (1997). A história do Projeto Unesco: estudos raciais e ciências sociais no Brasil. Tese de Doutorado. Instituto Universitário de Pesquisas do Rio de Janeiro.

Martins, José de Souza. (I998). Florestan: sociologia e consciência social no Brasil. São Paulo: Edusp/Fapesp.

Rios, Flávia M. (20I4). Elite política negra no Brasil: relação entre movimento social, partidos políticos e Estado. Tese de Doutorado. PPGS/Universidade de São Paulo.

Sereza, Haroldo C. (2005). Florestan: a inteligência militante. São Paulo: Boitempo. 
Silva, Mário A. M. da. (2013). A descoberta do insólito: literatura negra e literatura periférica no Brasil (I960-2000). Rio de Janeiro: Aeroplano.

Silva, Mário A. M. da. (2012). Fazer história, fazer sentido: Associação Cultural do Negro (I954-I964). Lua Nova, São Paulo, 85, p. 227-273.

Silva, Mário A. M. da. (20II). Reabilitando Virgínia Leone Bicudo. Sociedade e Estado, Brasília, I/26, p. 435-445.

Silva, Viviane Angélica. (2015). Cores da tradição: uma história do debate racial na Universidade de São Paulo e a configuração racial do seu corpo docente. Tese de Doutorado. Faculdade de Educação/Universidade de São Paulo.

Sotero, Edilza C. (20I5). Representação política negra no Brasil pós-Estado Novo. Tese de Doutorado. PPGS/Universidade de São Paulo.

Velho, Otávio G. (1983). Processos sociais no Brasil pós-64: as ciências sociais. In: Sorj, Bernardo \& Almeida, Maria H. T. de (orgs.). Sociedade e política no Brasil pós-64. São Paulo: Brasiliense. 
Palavras-chave

Intelectuais negros;

ativismo;

luta antirracista;

Florestan Fernandes;

Associação Cultural do Negro.

Keywords

Black intellectuals; activism;

antiracist struggle;

Florestan Fernades; Associação Cultural do Negro.

\section{ÓRBITAS SINCRÔNICAS: SOCIÓLOGOS E INTELECTUAIS NEGROS EM SÃO PAULO, ANOS 1950-1970}

\section{Resumo}

Procuro discutir a aproximação entre uma geração de sociólogos paulistanos, pesquisadores das relações raciais no Brasil, entre os anos I950 e I970, com ativistas e intelectuais negros de São Paulo. O foco se dá nas aproximações entre Florestan Fernandes e a Associação Cultural do Negro, permitindo retroceder e avançar no tempo, vislumbrando-se outras figuras igualmente importantes como Roger Bastide, Virgínia Leone Bicudo, Octavio Ianni, Eduardo de Oliveira e Oliveira. A hipótese é de que há uma aproximação de projetos políticos acerca da mudança social pautada pela luta antirracista, que se modificará em função do golpe de Estado civil-militar de 1964 .

\section{SYNCHRONIC ORBITS: SOCIOLOGISTS AND BLACK INTELECTUALS IN SÃO PAULO, 1950s-1970s}

\section{Abstract}

In this article, I discuss the relations established between a generation of sociologists from São Paulo, researchers on the subject of race relations in Brazil between the I950s and I970s, with black activists and black intellectuals in the same city. The focus is on the connection between Florestan Fernandes and the Associação Cultural do Negro, which allows me to shift back and forward in time, highlighting other important figures, such as Roger Bastide, Virgínia Leone Bicudo, Octavio Ianni, Eduardo de Oliveira e Oliveira, among others. My hypothesis is close relations were formed around the political projects for social change rooted in the antiracist struggle that made this alliance possible, until the situation changed with the I964 civilmilitary coup in Brazil. 